\title{
Area-based programming in fragile- and conflict-affected contexts
}

Huma Haider

Independent consultant

19 November 2021

\section{Question}

What is the evidence behind area-based programming in fragile- and conflict-affected states (FCAS) - with particular focus on Afghanistan - and what are the strengths and weaknesses of such an approach?

\section{Contents}

1. Summary

2. What is area-based programming?

3. ABP in Afghanistan and other FCAS

\section{Afghanistan}

Other country and regional examples

4. Benefits and factors of success

5. Weaknesses and challenges

6. Lessons and recommendations

7. References

Suggested citation

About this report

The K4D helpdesk service provides brief summaries of current research, evidence, and lessons learned. Helpdesk reports are not rigorous or systematic reviews; they are intended to provide an introduction to the most important evidence related to a research question. They draw on a rapid deskbased review of published literature and consultation with subject specialists. 


\section{Summary}

Area-based programming (ABP $)^{1}$ is an approach that defines an area as the primary entry point, rather than a sector or target group (USWG, 2019; Vrbensky, 2008). It is particularly appropriate in areas with complex, inter-related and multi-sectoral needs (USWG, 2019). It adopts a multisector and multi-stakeholder perspective; and a participatory, inclusive and bottom-up approach, overlapping with community-based development processes and mechanisms.

Evaluations of $A B P$ suggest that such an approach can be effective in responding to complex conflict characteristics on sub-national levels (UNDP, 2018). Despite growing interest in ABP, however, evidence is still greater for sectoral or issue-based approaches than for area-based approaches (UNDP, 2018). There is limited evidence or guidance on the programming practicalities of implementing ABP (Bogdanov \& Nikolić, 2013). The adoption of area-based approaches in cross-border rural areas of the Western Balkans are some of the earliest of such interventions discussed and evaluated. There has in recent years been an increase in discussion and case studies of the application of ABP in urban settings. This rapid literature review looks at area-based approaches in rural and urban settings, focusing on Afghanistan, along with a brief look at examples from Syria, Lebanon, Mauritania, and the Western Balkans. It draws out collective strengths, factors of success, and weaknesses and challenges from these country and regional programmes. It concludes with a list of lessons and recommendations.

\section{Benefits and factors of success}

- Geographic delineation: The local perspective allows for better understanding of the area's circumstances, needs and capacities (UNDP, 2014; Vrbensky, 2008).

- Economic development and well-being: The ABP approach has contributed to economic growth and improved the well-being of local populations, such as villagers in Afghanistan who gained job opportunities (Akbari \& Rahmani, 2020), and rural smallholders in the Western Balkans, through enhanced competitiveness, value chain development, income generation and employment (Pavloska Gjorgjieska et al., 2019; Surlevski et al., 2018). The involvement of local people can build human capital (UNDP, 2018; Vrbensky, 2008).

- Social cohesion: Social integration, the involvement of entire communities, and reductions in perceptions of social inequality have often been noted as positive results of ABP (Santini et al., 2012; Vrbensky, 2008). Participatory and inclusive tools and approaches in urban settings have brought together people across divides, helped to build trust and strengthened community cohesion, such as in Afghanistan (French et al., 2019; USWG, 2019).

- Local governance: This has been strengthened through support to capacity building of local administration, institutional development and organisational reform (Vrbensky, 2008).

- Scaling up: Bottom-up sub-national approaches need to be coherent with the macro level. In the Western Balkans, the Delphi group (experts familiar with national policies), which was set up to provide a proper link with top-down national policies, helped to resolve conflicting priorities (Saravia-Saravia-Matus et al., 2013; Santini et al., 2012).

\section{Weaknesses and challenges:}

- Geographic delineation: ABP approaches can increase inequalities between the target area and surrounding areas and create tensions with external residents (USWG, 2019).

\footnotetext{
${ }^{1}$ Also referred to as placed-based, neighbourhood or settlements-based approaches.
} 
- Manageability versus inclusivity: The number and complexity of stakeholders has led to difficulties in ABP in urban settings (USWG, 2019). CDCs in Afghanistan experienced tension between getting things done and fostering inclusiveness (French et al., 2019).

- Ownership and participation shortfalls: Power politics can favour specific voices (Sanyal, 2021). Research on the National Area-Based Development Programme in Afghanistan finds that projects have been selected for simplicity or political reasons, rather than based on community priorities (UNDP, 2014). Securing meaningful participation of women has been challenging (French et al., 2019). Participation has also been 'selective' in the Western Balkans, based on pre-existing networks (Saravia-Matus et al., 2013).

- Social cohesion challenges: While strengthened social cohesion can be a key benefit of $\mathrm{ABP}$, a degree of pre-existing social cohesion can also be necessary. Including displaced Syrians and Lebanese host populations in committees has been challenging as they diverge on ideas of 'community' (Sanyal, 2021). Research on the Citizens' Charter in Afghanistan finds that there has been more measurable success in the creation of physical infrastructure than in social outcomes (Lillehaugen et al., 2020). The selection of construction works has also had an indirect bias against women as it is often a male-dominated field (USWG, 2019).

- Complexity: Programmes in disaster contexts have in some cases been considered too complicated, with leaders defaulting to a traditional single-sector, input-driven approach (Sanderson, 2017). The 'Urban Displacement Out of Camps' programme in Afghanistan was constrained by its lack of formal coordination mandate, with humanitarian workers resorting to traditional approaches (Konyndyk et al., 2020).

- Scaling up: Focusing on a defined area can result in inadequate attention to the macro-level context and linkages to the national context, through which to respond to structural issues (Vrbensky, 2008). ABP thus risks shifting responsibility onto local stakeholders when national or international action is required (USWG, 2019). Research on the Citizens' Charter in Afghanistan finds that when CDC-level infrastructure interventions are not connected to precinct- and city-level infrastructure, it can exacerbate urban problems (French et al., 2019).

- Funding and sustainability: Community-level funding has produced differing outcomes in urban areas with higher and lower socio-economic profiles in Afghanistan (French et al., 2019). The absence of solid long- or medium-term financing can weaken the overall process (Saravia-Saravia-Matus et al., 2013).

- Measurement: Area-based approaches require multi-agency measurement of contribution, rather than single-agency measurement of attribution (Sanderson, 2017). Research on areabased approaches in disaster contexts finds, however, that log frames with a single sector focus, or that measure inputs versus outputs, continue to undermine ABP (Sanderson, 2017).

\section{Lessons and recommendations}

- Defined area: The target area needs to be well focused, with a degree of uniformity in its development challenges, priorities and needs (USWG, 2019; Santini et al., 2012).

- People-centred and participatory-based: There needs to be meaningful, early and ongoing engagement with all impacted population groups (USWG, 2019; Santini et al., 2012).

- Realistic time frame and sustainability: ABP requires enough time and resources to bring together multiple stakeholders and to build relationships (USWG, 2019).

- Enabling context: Urban settings with an existing multi-sectoral coordination system or culture; more cohesive community; and with a local government supportive of ABP, are more conducive to effective area-based approaches (USWG, 2019; Sanderson \& Sitko, 2017).

- Flexibility: approaches must be flexible, adaptive, and highly responsive to situational changes in the defined area and to shifts in priorities (USWG, 2019; Vrbensky, 2008). 
- Existing systems: area-based approaches can be strengthened if they work with existing systems of local governance and service delivery (USWG, 2019; Sanderson \& Sitko, 2017).

- Coordination: institutional mechanisms for information flow can bring together sectoral actors to create a shared plan and implement a collective response (Schell et al., 2020).

- Multi-agency contribution: M\&E should focus on multi-agency contribution to change rather than single-agency attribution of outputs/outcomes (USWG, 2019; Sanderson \& Sitko, 2017).

- Scaling up: ABP should link to macro-level situations, including higher-level government policies and plans and markets (Sanderson, 2017; Santini et al., 2012). Scaling up also applies to planning for replication of ABP in other geographical areas (Sanderson, 2017).

\section{What is area-based programming?}

Area-based programming (ABP) is an approach that defines an area as the primary entry point, rather than a sector or target group (USWG, 2019; Vrbensky, 2008). This approach is particularly appropriate in areas with complex, inter-related and multi-sectoral needs (USWG, 2019). A key strength of the approach is developing a deeper understanding of the affected population's holistic needs, and building on existing community cohesion, governance structures, markets, and service delivery mechanisms (USWG, 2019).

The particular fragile- or conflict-affected context determines the exact set of strategies and activities to be included in the programme (Vrbensky, 2008). The problems to be addressed through area-based approaches fall into four main categories (Harfst, 2006):

- Conflict-related: pre- or post-conflict situations affecting a specific area of a country that requires preventive development actions, reconstruction, peacebuilding and reintegration.

- Disaster-related: natural and/or manmade that affect a specific area of a country.

- Poverty-related: 'spatial poverty traps' that have emerged as a result of geographical isolation, climate, terrain, demography, or economic restructuring.

- Exclusion-related: groups/categories of marginalised and excluded people concentrated in a specific part of a country, such as regional ethnic minorities.

Key characteristics of area-based approaches include:

Specific geographic area: ABP targets a defined geographic area, with a high level of need, delineated by physical, social or administrative boundaries (or a combination) (Schell et al., 2020; USWG, 2019). It should be possible to address the problems or needs at the level of the delineated area (Harfst, 2006). Such areas can vary in scale from neighbourhoods, to wards and districts, to the whole town or city - or even to cross-border regions (Schell et al., 2020).

Multi-sectoral: ABP typically involves intervention in multiple sectors, at multiple levels, and involving multiple segments of society in an integrated manner (Vrbensky, 2008). This can include sectors such as health, education, housing, livelihoods, social safety nets, water, and sanitation - considering needs, capacities, and access to services across all sectors (Sanyal, 2021; Schell et al., 2020; USWG, 2019). While it may not be possible to address all needs, all individuals in the target area should receive a level of support appropriate to their relative needs (such as access to improved public spaces, information, or training) (USWG, 2019).

Multi-stakeholder and participatory: ABP seeks to actively engage numerous, diverse stakeholder groups present in the target area, including local authorities, local civil society and 
service providers, international humanitarian and development actors, the private sector and the affected community (Schell et al., 2020; Vrbensky, 2008). The approach is bottom-up and participatory, and tends to be more accessible to local actors, centred more explicitly on how affected people define their own priorities (Konyndyk et al., 2020; Vrbensky, 2008).

Inclusive: The approach includes the whole population of an area, regardless of their legal status, risk category or particular vulnerability, rather than targeting specific groups (Schell et al., 2020; Vrbensky, 2008). The whole population includes transient (e.g. refugees) and long-term residents who could be affected in different and similar ways (USWG, 2019).

The ABP approach embodies characteristics that are common to rural development models and community-based development, such as inclusion, participation, and bottom-up initiatives (UNDP, 2018). The integrated nature of the ABP approach has also gained traction with rural development (UNDP, 2018). It is increasingly recognised, for example, that sustained rural development requires attention beyond agricultural issues, integrating environmental, sociopolitical and institutional aspects (UNDP, 2018; Saravia-Matus et al., 2013). In recent years, the ABP approach has also gained prominence amongst humanitarian workers working in fragile urban contexts that house refugees, displaced persons, and host communities. Interventions are needed on many levels, encompassing the whole population (Sanyal, 2021; González, 2016).

\section{ABP in Afghanistan and other FCAS}

The following is a brief overview of completed or ongoing area-based programming in Afghanistan, Syria, Lebanon, Mauritania, and the Western Balkans. While the programmes and approaches are outlined here, discussion of various strengths, weaknesses and challenges of these programmes are discussed together in sections 4 and 5 .

\section{Afghanistan}

The National Area-Based Development Programme (NABDP) (2002-2015) is a large programme that was implemented in rural areas all over the country. Its aim was to contribute to poverty reduction through attention to building social, irrigation and transport infrastructure, and to local governance. The medium-size infrastructure projects were selected in a participatory manner by representative District Development Assemblies (DDAs) (UNDP, 2014). Through the DDAs, the NABDP emulated and built upon the National Solidarity Programme (NSP) and its use of traditional local governance councils (shuras) to plan development, thus relying on local social capital, knowledge and identification of needs (UNDP, 2014). A beneficiary assessment finds, however, that the NABDP should have given more attention to community organisation, rather than the greater focus given to the physical infrastructure projects (UNDP, 2014).

Spanning rural and urban areas: The NABDP and NSP focused on rural areas in Afghanistan. Recent literature points to the need to address prior neglect of investment and programming for cities, with the implications of this shortfall evident in many urban settings (French et al., 2019). In some cases, international donors have retained sectoral approaches to aid, rather than areabased approaches, in urban settings, reflecting inadequate understanding of the complexities of urban development, particularly in the context of rapid urbanisation (French et al., 2019).

In Afghanistan, the history of recurrent conflict, displacement, and return has produced many communities where returned refugees and internally displaced persons (IDPs), and highly 
vulnerable host community members live side by side. Since the beginning of 2016 , over 1 million Afghans have returned from Pakistan (USWG, 2019). Interventions that focus only on one category of vulnerability, such as returnees or refugees, which has been common, can contribute to intra-community tensions (Konyndyk et al., 2020). ABP can highlight and address the displacement dynamics that affect communities at large (Konyndyk et al., 2020).

UN-Habitat's urban CDC approach is very similar to that of village Community Development Councils (CDCs) under the NSP. The NSP targeted rural areas, whereas UN-Habitat applied the NSP model in cities in cooperation with municipalities (French et al., 2019). An urban CDC includes on average 200-250 neighbouring households in a defined area (French et al., 2019). The project cycle includes raising community awareness through gatherings; establishment of CDCs through elections open to all neighbourhood residents; development of an action plan, identifying local needs, priorities, and resources; sub-project design and approval by the municipality; and project implementation and monitoring (French et al., 2019). A Gozar Assembly (GA), comprised of a cluster of an average of five CDCs, is the next level in local governance, with a mandate to address larger-scale issues and to act as the institutional link between CDCs and the nahia (District) (French et al., 2019). CDCs and GAs assume other functions beyond infrastructure sub-projects, such as developing neighbourhood conflict resolution subcommittees, generating livelihoods support activities, implementing literacy skills development initiatives, and fostering civic responsibility (French et al., 2019).

The Citizens' Charter National Priority Programme (CCNPP), beginning in 2016, goes further than the NSP and extends support to urban settings, while also bringing CDCs to the forefront of programme delivery (Akbari \& Rahmani, 2020). The CDCs and Gozar Assemblies will be linked to the sub-national government to improve communication and coordination from the community to the district, provincial and national levels (Akbari \& Rahmani, 2020; Lillehaugen et al., 2020). The community engagement feature and participatory processes of the Citizens' Charter are designed to ensure that all segments of a community have a voice in the prioritisation process and in identifying obstacles to economic returns (Lillehaugen et al., 2020). The recruitment of local workers and requirement for community contributions can also lower the overall costs of the programme, ideally contributing to efficiency and sustainability (Lillehaugen et al., 2020).

Norwegian Refugee Council (NRC)'s 'Urban Displacement Out of Camps' initiative adopted an area-based approach to promote more consistent access to humanitarian services across different sectors and population categories in eight districts with high levels of return (Konyndyk et al., 2020). A community-based assessment and mapping exercise enabled community members to identify key information needs, existing services and capacities, and opportunities to engage (Konyndyk et al., 2020; USWG, 2019). The project established Community Centres, Mobile Outreach Teams, and representative Neighbourhood Committees in neighbourhoods within the wider target areas. The aim was to improve access to information on services, address gaps in coordination, consult on needs of returnees, IDPs and host populations, and allow for community mobilisation (Konyndyk et al., 2020; USWG, 2019). The Mobile Teams in particular have enabled an entry point for community members to access service providers (USWG, 2019).

\section{Other country and regional examples}

Syria: Urban planning and land management issues in Syria are complicated and multidisciplinary, including numerous institutions at the local, regional, and national levels (Ayad, 2012). Area-based programming has been adopted in Syria, aimed at improving service delivery to the poorest urban communities and promoting regional equity, while addressing the needs of 
vulnerable groups, through multi-sectoral regional-based development plans (Ayad, 2012). A notable example is an area-based approach applied in Ar-Raqqa, in the North and East Syria region (NES) (Schell et al., 2020). To support affected populations, REACH7 undertook a series of area-based assessments in partnership with the NES NGO forum. The assessments provided a comprehensive overview across the city and at the neighbourhood level, including mapping returns, needs, the state of services and infrastructure, and access (Schell et al., 2020). Findings from the multi-sectoral assessments informed response priorities. This process has since expanded to several other towns and cities across Syria (Schell et al., 2020).

Lebanon: Large numbers of displaced Syrians have moved to rural and urban areas in Lebanon and to other countries in the Middle East, often into poor areas, where they can access cheaper housing options (Sanyal, 2021). The influx of large numbers of refugees into many municipalities has overwhelmed local communities in Lebanon and compounded pre-existing challenges faced by local administrators (Sanyal, 2021). Neighbourhood approaches have been adopted in urban settings, such as in Tripoli, through community committees, considered to be key actors in the understanding of neighbourhood boundaries and the implementation of projects (Sanyal, 2021). Committees made up of 6-7 people were mostly women, despite attempts to diversify by gender and age, and were later combined into larger committees (Sanyal, 2021).

Mauritania: The Mbera camp and host communities in Mauritania are in a region with poor road infrastructure and limited access to health services and education. The arrival of refugees has increased food insecurity in the area, affecting in particular the most vulnerable households and refugees (González, 2016). Mbera Camp allows local communities to access services, such as water and sanitation, education and health; however, host populations do not have access to food distribution and other non-food items, which are reserved for refugees (González, 2016). Host communities and refugees experience many of the same challenges, including forms of gender-based violence (GBV), which may increase if entire communities are under stress in fragile contexts (González, 2016). It can thus be beneficial to adopt an area-based approach recognising all populations in an area, working on a multi-sectoral prevention and response plan that addresses the needs of all women and men, girls and boys in the area (González, 2016).

Western Balkans: The 'Area Based Development (ABD) Approach' in the Western Balkans is an ongoing initiative, developed and implemented by the Regional Rural Development Standing Working Group (SWG) in South Eastern Europe. The complex interdependence of poverty, social exclusion, ethnic tensions, and administrative burdens in cross-border regions has called for inclusive, participatory and flexible interventions (llic \& Dzimrevska, 2015). A multi-sectorial approach is also necessary. In the case of the Drina-Tara (Bosnia and Herzegovina, Montenegro and Serbia), for example, the identified priority areas of tourism, natural resources, and agricultural and rural development overlap with regard to small and medium enterprise development, rural tourism, and environmental protection (Santini et al., 2012).

Participation of ethnic minorities is particularly important as border areas are characterised by a higher density of ethnic minorities (llic \& Dzimrevska, 2015). Several participatory instruments and processes have been adopted to create the basis for a multi-stakeholder approach to local development; and to gather information for the identification of development needs (SaraviaMatus et al., 2013). Participatory mechanisms include Stakeholder groups (SHG) (with representatives of the public, private and civil sectors); Delphi groups (DG) (a range of 'experts'); and surveys of community representatives (Surlevski et al., 2018; llic \& Dzimrevska, 2015; Saravia-Matus et al., 2013). Project Management Units (PMUs) act as coordination bodies for the members of the SHGs in each of the regions (Surlevski et al., 2018). 


\section{Benefits and factors of success}

Geographic delineation and local focus: Conflicts are often localised, with delineation of areas of conflict and relatively stable areas (Vrbensky, 2008). Where conflict characteristics and their manifestations are largely local, the local perspective and proximity to issues and beneficiaries is a key benefit of ABP, allowing for better understanding of the area's circumstances, needs and capacities (UNDP, 2014; Vrbensky, 2008). This can also help to preserve the stability of the broader country or region, 'insulating' other areas from the conflict (Vrbensky, 2008).

Economic development and well-being: A research survey on Afghanistan's CCNPP finds that 82 percent of people interviewed were strongly satisfied with the community's implementation of the development programme, as it was driven by villagers' needs and creates local job opportunities (Akbari \& Rahmani, 2020). The ABD approach in the Western Balkans is also considered effective in fostering integrated economic growth in rural cross-border regions (Surlevski et al., 2018). This success derives in part from the use of a participatory, peoplecentred approach that allows for better understanding of the realities of the rural population and identification of priorities (Surlevski et al., 2018). The ABD approach in Drina-Sava, for example, improved the economic wellbeing of involved rural smallholders through enhanced competitiveness, income generation and employment (Pavloska Gjorgjieska et al., 2019). This was achieved through the creation of business networks among rural smallholders and with other key stakeholders; involvement in policy dialogue platforms; targeted capacity building measures; and grants for multi-sector small-scale investments in tourism and agricultural production and processing, focusing on sustainable use of natural resources (Pavloska Gjorgjieska et al., 2019).

Human capital: Research on ABP approaches finds that the involvement of local people and local empowerment can build human capital, with local people becoming agents of change (UNDP, 2018; Vrbensky, 2008). In the case of CDCs in Afghanistan, training in the process of infrastructure delivery - from the initial training on procurement and accounting to the process of constructing the infrastructure itself, has provided community members with a foundation for more thorough engagement in development work (Lillehaugen et al., 2020). Targeted urban communities as part of ABP approaches in Afghanistan have also benefited from increased skills through vocational training programmes (USWG, 2019). In Syria, ABP activities involved building capacities of local communities and local and regional authorities, including formulating planning standards and regulations; and learning new methodologies, management tools, and informatics necessary for supporting planning and management processes (Ayad, 2012).

Value chain development: The ABD approach in the Western Balkans aimed to involve all stakeholders, including the private business sector, with a focus on value chain development, integration of small business operators in the value chains, and increasing the quality of local, traditional products and tourist services (Surlevski et al., 2018). The Prespa Business Forum, established as part of the ABD approach, established a common network platform in the area of agriculture, tourism and food industry, business cooperation. This could aid in discovering common markets that will contribute to economic development of the cross-border region (Surlevski et al., 2018). Networking and cooperation among stakeholders in rural areas - and the exchange of experiences and know-how - can also boost activities, help to resolve problems or add value to local resources, products and services (Surlevski et al., 2018). Efforts have been made to create a regional identity and branding, including identifying and registering all relevant business operators in the ABD regions (Surlevski et al., 2018). 
Social cohesion: Social integration, non-discrimination through the involvement of the entire community, and reduction of the perception of social inequality - while difficult to measure - have often been mentioned by interviewees as positive results of ABP (Vrbensky, 2008). A focus on 'place-making', prominent in ABP approaches can foster a sense of community identity, along with focusing on unifying rather than dividing issues (Sanderson, 2017; Vrbensky, 2008). Research on ABD in the rural cross-border regions of the Western Balkans finds that participatory processes and the selection of action plans that benefit the entire target area can produce a sense of social cohesion (Santini et al., 2012). Other research finds that the peoplecentred, participatory approach promoted the cultural, traditional, and natural heritage of the cross-border regions, alongside cooperation and economic development (Surlevski et al., 2018). It also contributed to processes of reconciliation among the different nationalities and ethnic groups living and operating in the cross-border regions (Surlevski et al., 2018).

Participatory and inclusive tools and approaches in urban settings have also helped to build trust and strengthen community cohesion (USWG, 2019). Research on the CDCs in urban settings in Afghanistan finds that social cohesion is seen to derive from the willingness of residents within the CDC boundary to put aside differences to come together to plan and implement projects (French et al., 2019). Research on the Citizens' Charter in cities in Afghanistan finds that in addition to physical outputs, there have been valuable social impacts. These include:

- improved community cohesion and solidarity, with reduced ethnic tensions;

- a greater sense of local unity amongst diverse groups;

- an increased sense of belonging in cities;

- improved relations with municipality and service providers; and

- improved engagement of citizens, including women and youth, in civic life, decision-making and conflict resolution (French et al., 2019).

Other research on the Citizens' Charter also finds that studied communities reported social changes, including the increased role of women in community life and in collective efforts to address the needs of vulnerable community members (Lillehaugen et al., 2020). Research on the Kabul Area Shelter and Settlements (KASS) finds that the strong engagement of community representatives at the neighbourhood level, including Gozar Assemblies and informal community leaders, in defining needs, response priorities and implementation, created a vibrant community integrated into Kabul. This contrasts with an isolated ghettoised community, which has been the outcome of other resettlement programmes targeting only returnees (USWG, 2019).

Refugees, IDPs and host communities in fragile urban settings often face similar challenges and are in potential competition for survival (USWG, 2019; González, 2016). Interventions focused on only one category of vulnerability (i.e. displaced persons) - and disparate levels of support to different categories of households - can contribute to intra-community tensions. They can also be ineffective in addressing interrelated needs (e.g. protection from GBV) that these commingled populations jointly face (Konyndyk et al., 2020; González, 2016). Area-based approaches can prevent the unintended consequence of such tensions.

UN-Habitat operated in a number of cities in Afghanistan, supporting a programme that came to be known as the 'people's process', which identified common priorities among returnees, IDPs, demobilised combatants and low-income households (Schell et al., 2020). In the NRC's approach, the establishment of neighbourhood committees, linked to local service providers and authorities, enabled displaced residents and the wider host community to address their collective 
concerns across multiple technical sectors (water supply, education, and health facilities) (Konyndyk et al., 2020; USWG, 2019). NRC also facilitated local coordination meetings with neighbourhood committees alongside a range of local organisations, authorities, informal community leaders, and NGOs (USWG, 2019). In Lebanon, NGOs have also experimented with neighbourhood approaches, recognising that living areas in many urban settings pose significant problems for Syrian refugees and host communities alike, in the areas of shelter, public services and sanitation (Sanyal, 2021; Schell et al., 2020). A geographical approach that supports both Syrians and Lebanese can reduce conflict between them, while improving their mutual living conditions and strengthening community governance (Sanyal, 2021; Schell et al., 2020). Similarly, in Mauritania, attention to the shared needs of preventing GBV among refugees and host populations calls for a multi-sectoral prevention and response plan that addresses the needs of all women and men, girls and boys in the area (González, 2016).

Local governance: Support to local governance is considered a key aspect and successful component of the ABP approach (Vrbensky, 2008). This has been achieved through capacity building of local administration and supporting institutional development and organisational reform at the municipal level, which in turn has contributed to decentralisation of power (Vrbensky, 2008). Higher levels of interaction between local government and civil society and the public also helps to build legitimacy and effectiveness in service delivery (Vrbensky, 2008). Case studies of ABP approaches in urban settings point to the important achievement of building the capacity of local actors and strengthening relationships between communities and government, as in the case of Tripoli, Lebanon and Aleppo, Syria (USWG, 2019).

Scaling up: Research on ABP often mentions the need to ensure a proper link with top-down national policies, in order to ensure that bottom-up sub-national approaches are coherent with the macro level situation (USWG, 2019; Sanderson, 2017; Saravia-Saravia-Matus et al., 2013; Santini et al., 2012) (See Section 6: Lessons and Recommendations). In the Western Balkans, the Delphi group was set up to provide a proper link with top-down national policies. It comprised a group of experts familiar with national policies and with an international perspective to local problems, who could facilitate the introduction of top-down perspectives. This in turn allowed for synergy between bottom-up and top-down perspectives (Saravia-Saravia-Matus et al., 2013). Of the DG's 11 members, four represented national authorities, five came from academia, and two were experts in fields related to regional economics, agriculture and sustainable development (Saravia-Saravia-Matus et al., 2013). Research finds that the contributions of the DG helped to resolve conflicting priorities (e.g. hydro-electricity national priorities vs. agriculture / tourism vs. agriculture) (Santini et al., 2012). It was challenging, however, when experts expressed different opinions and when local stakeholders perceived a degree of paternalism from the group (Saravia-Saravia-Matus et al., 2013). Area-based approaches can also link with wider plans for the city or region by working alongside other types of interventions, such as support to strengthening local governance (USWG, 2019).

\section{Weaknesses and challenges}

Geographic delineation - exclusion and diversity: Research on ABP in cities finds that focusing assistance on high profile areas can increase inequalities between the target and surrounding areas and create tensions (USWG, 2019). In post-2001 Afghanistan, rural areas were the primary target for support which resulted in neglect of investment and programming for cities (French et al., 2019). In rural areas too, the NABDP directed much greater funding to more accessible districts and to a few insecure provinces, with remote locations and more secure 
provinces receiving a fraction of funding (UNDP, 2014). Research on ABD programming in the Western Balkans finds that some municipalities outside the target area share basic development problems - and geographical, human, and socio-economic features - with some that are included. The inclusion/exclusion of areas was thus not well justified (Santini et al., 2012).

There is also an implicit assumption that neighbourhoods are homogenous with shared values and interests, which will translate into consensus over plans. This is, however, not necessarily the case (Sanyal, 2021). Race and class and other identities play important roles in how neighbourhoods and their boundaries are imagined and mobilised (Sanyal, 2021). Area-specific activities may also lead to fragmentation, where local approaches suffer from partial thinking, design and realisation, resulting in fragmented solutions and duplications (Vrbensky, 2008).

Manageability versus inclusiveness: Research finds that the balance often leans towards manageability at the expense of inclusiveness (Vrbensky, 2008). The number and complexity of stakeholders has led to difficulties in ABP in various urban settings (USWG, 2019). Research on CDCs in urban settings in Afghanistan finds a recurring tension between a community-led model to get things done, on the one hand, and fostering meaningful citizen participation with lasting social impacts, on the other (French et al., 2019). Research on the 'neighbourhood approach' in Lebanon finds that while participation in planning issues is encouraged, it is also resource intensive and a smaller group of community representatives ends up being involved, resulting in exclusionary consultations (Sanyal, 2021). In the Western Balkans, a key challenge in implementing ABD programming was also being inclusive without reaching too large a number of stakeholder group members that would have made consensus too costly (Saravia-Matus et al., 2013). The diversity of SHG members made it difficult in some cases to reach consensus and to formulate and refine an action plan (Saravia-Matus et al., 2013; Santini et al., 2012).

Participation shortfalls: The NABDP sought to strengthen democratic representation by establishing DDAs through a formal election process and opening them to women's participation. While female participation was easily set up in some areas (e.g. in Herat and Balkh), the NABDP struggled in other areas (e.g. in the eastern and southern provinces, including Kabul) to secure female DDA members because of cultural restrictions preventing strong female participation in the public sphere (UNDP, 2014). Women were sometimes not invited to DDA meetings or were physically unable to attend the meetings. Formal participation thus does not necessarily translate into increased substantive female participation in decision-making (UNDP, 2014). Research on ADP in cities in Afghanistan also finds that there remains insufficient meaningful engagement of women, youth, IDPs, and other vulnerable and marginalised groups, who have not been systematically brought into the process to participate to their full potential (French et al., 2019). In addition, research on the NABDP finds that the selection of micro-projects for NABDP funding seemed to favour simple, discrete projects that could be pushed through the system faster, such as micro-electric schemes, road graveling or canal clearing projects, which are not necessarily the highest priority for the community (UNDP, 2014). Afghan politicians have also influenced the selection of funded projects (UNDP, 2014).

Participation in ABP in other contexts are also considered to be subject to power politics in which some voices are silenced by those that are more powerful (Sanyal, 2021). Research on ABD programming in the Western Balkans finds that representatives selected to the SHG had to be opinion leaders and were often selected based on pre-existing networks, rather than based on democratic procedures (Saravia-Matus et al., 2013). Participatory processes also require much more time than the one (six months at most) dedicated to the Drina-Tara case to achieve a real 
internalised consensus on development priorities and to apply appropriate analytical tools (Santini et al., 2012).

Social cohesion challenges: While research on ABP often identifies strengthened social cohesion as a key benefit of the approach, it may be the case that a degree of social cohesion is required as a pre-existing condition for $\mathrm{ABP}$ to be effective. There may also be an implicit assumption that neighbourhoods are homogenous with shared values and interests, which will translate into consensus over plans. This is, however, not necessarily the case (Sanyal, 2021). Race and class and other identities play important roles in how neighbourhoods and their boundaries are imagined and mobilised (Sanyal, 2021). In Afghanistan, the length of time living in a settlement, historical social ties, household bonds, and a sense of shared local history influenced whether a neighbourhood was fitting for an area-based approach and could engage in constructive community action (French et al., 2019). In contrast, weaker social ties in areas that have relatively recent returnees, high numbers of displaced persons, and/or recent rural-urban migrants, can make community mobilisation more challenging (French et al., 2019). Including displaced Syrians and Lebanese host populations in committees in Lebanon, for example, was challenging as they often have different ideas of neighbourhood and community. (Sanyal, 2021). The deteriorating socio-economic situation in Lebanon also led to inter-group tensions, which undermined social cohesion, the functioning of committees, and project success (Sanyal, 2021).

Research on the Citizens' Charter in Afghanistan finds that community-driven development has achieved more measurable success in the creation of physical infrastructure than in the attainment of certain social outcomes (Lillehaugen et al., 2020). This is due largely to the greater complexity of such efforts, the challenges of measuring such change, and the longer timeframe required for social change (Lillehaugen et al., 2020). These outcomes reflect general trends observed in studies of the NSP, where infrastructure was delivered successfully, but impacts on social cohesion were either short-lived or insignificant (Lillehaugen et al., 2020). Further, community-led urban infrastructure programmes in Afghanistan have had an indirect bias against women in project selection, as construction works, which are a key interest of stakeholders, is often a male-dominated field (USWG, 2019). A higher representation of women is needed in order to achieve greater support for more gender-balanced sub-projects (USWG, 2019).

Complexity: Research on urban area-based approaches in disaster contexts finds a tension between hiring skilled sectoral personnel versus multidisciplinary staff. In some instances, programmes were considered 'too complicated', with leaders insufficiently invested in the programme, resulting in defaulting to a traditional single-sector, input-driven approach (Sanderson, 2017). It was also considered a big challenge to have qualified managers in place that could navigate the complexities and achieve more successful area-based programming. For urban programming, for example, staff management profiles, and thus, job descriptions, require more of a combination of social entrepreneur, negotiator and networker rather than of an engineer, or a house builder or logistician (Sanderson, 2017).

Research on ABD programming in the Western Balkans finds that its complex, multi-sectorial nature can lead to inadequate coordination between implementing agents (Santini et al., 2012). In addition, it can be the case that the multi-sectorial approach is incomplete because significant elements have been left aside in the action plans (e.g. waste management, river quality issues, and broadband access and language skills required for tourism) (Santini et al., 2012). NRC's 'Urban Displacement Out of Camps' programme was constrained by its lack of formal coordination mandate. Humanitarian service providers in some cases resorted back to the did not always engage responsively, as the standard humanitarian approach differs from a holistic, 
context-centred approach (Konyndyk et al., 2020). NRC's ability to promote access to services often depended more on personal relationships than formal coordination (Konyndyk et al., 2020).

Scaling up: Concentrating on a defined area, a key feature of ABP, could result in inadequate attention to, understanding of, and connection to the broader, macro-level context. This includes structural factors (e.g. policies) that contribute to the conflict or developmental problem (Vrebensky, 2008). Even if there is an adequate understanding of the broader context, there need to be linkages to the national context, through which to respond to structural issues related to security, governance, poverty, and underdevelopment (Vrbensky, 2008). Otherwise, ABP could end up shifting responsibility onto local stakeholders when national or international action is required (USWG, 2019). In Serbia, for example, ABD programming needed greater involvement from the central government to achieve more effective programme implementation. While mid-level government officials were involved, decision-making on several key issues (e.g. inclusion of minorities in institutions, security, privatisation, education, and the environment) required higher-level government participation (Vrbensky, 2008). The absence of such involvement, and inability to address structural issues, can undermine the success of initiatives at lower levels (Vrbensky, 2008). More involvement of line ministries in guidance could multiply and scale-up the programme results (Vrbensky, 2008).

An evaluation of the NABDP finds that it has struggled with sustainability, with inadequate attention to operation and maintenance issues (UNDP, 2014). Stronger links with line ministries (e.g. for schools, clinics or public works) could help to alleviate this weakness (UNDP, 2014). In one example, the NABDP built a large hospital compound but the Ministry of Health could not immediately support it with staff and equipment, which resulted in the building remaining unoccupied for two years, until an NGO stepped in to support it (UNDP, 2014). There are other cases where NABDP-funded infrastructure has fallen into disrepair (UNDP, 2014).

Case studies of ABP in urban settings also finds that if poorly designed and implemented, areabased approaches can lead to a disconnect between local plans and wider city or regional plans (USWG, 2019). Research on the Citizens' Charter in Afghanistan finds that when CDC-level infrastructure interventions are not connected to precinct- and city-level infrastructure, it can exacerbate urban problems (French et al., 2019). This has been the case, for example, with surface drainage, where CDC roadside drainage channels have not always been connected to larger municipal drains and have subsequently exacerbated flooding in downstream neighbourhoods (French et al., 2019). CDCs may thus not be satisfactory mechanisms to implement municipal-level infrastructure, unless properly linked to wider precinct- and city-level plans (French et al., 2019). The aim should be to integrate CDCs and Gozar Assemblies into the municipal governance structure (French et al., 2019). CDC members have also made requests at conferences and public meetings for the government to endow then with stronger legal standing (Akbari \& Rahmani, 2020). A case study of KASS finds that there has been a high level of engagement from Kabul Municipality and Mayors offices, regular meetings, common understanding of issues and consensus building (USWG, 2019). Continued improvement of linkages between different levels of local governance is still needed: Gozar shuras with district shuras, District shuras with district offices, district offices with Kabul Municipality (USWG, 2019).

Research on the Mbera camp and surrounding area in Mauritania finds that there needs to be increased efforts to coordinate, communicate and report GBV and share data among humanitarian actors, civil servants, police, and other public officials working inside camps and in the surrounding areas. Only then can progress be 'scaled up' to counter GBV among both refugees and host communities (González, 2016). 
Funding and sustainability: The CCNPP is designed to cover the entire country over the course of three phases. It is possible, however, to continue in certain locations while suspending operations in others (Lillehaugen et al., 2020). Failure in one area could thus lead to cashflow issues that constrain the ability to implement the work elsewhere (Lillehaugen et al., 2020).

Community-level funding has produced differing outcomes in urban areas in Afghanistan. Research finds that it is more challenging to secure community contributions from CDCs with a higher socioeconomic profile - households that have a regular income, often through government employment (e.g. doctors, teachers, public servants) (French et al., 2019). These CDCs have a higher degree of tenure security and higher expectations that the government should implement upgrading works without requiring community contributions (French et al., 2019). In contrast, CDCs with lower socioeconomic levels, occupied by households relying on informal income (e.g. construction labour, street vending or shopkeeping), have less connection to, and trust in, government, and lower tenure security. They are more willing to invest personally in formalising their neighbourhood and strengthening tenure security (French et al., 2019).

Research on ABD approaches in the Western Balkans finds that the absence of solid long- or medium-term financing weakens the overall process of programming (Saravia-Saravia-Matus et al., 2013). In order to address this, fourteen municipalities of the Drina-Tara area, for example, entered into an informal but permanent commitment - the Drina-Tara Network, supported by a Memorandum of Understanding (Saravia-Saravia-Matus et al., 2013). The Standing Working Group-Regional Rural Development (SWG-RRD) also offered to serve as an institutional umbrella to facilitate funding and promote the execution of the different action plans. Local stakeholder groups thus have linkages with the national level, and access to the international community with the help of SWG-RRD (Saravia-Saravia-Matus et al., 2013).

Measurement: Area-based approaches require a different from of measurement - away from single-agency measurement of attribution (correlating the activities of one project to community benefits) to multi-agency measurement of contribution (how a project may have helped as part of a wider effort) (Sanderson, 2017). Focusing on contribution helps to move emphasis away from individual, isolated projects, and towards addressing overall issues and challenges (Sanderson, 2017). Research on urban area-based approaches in disaster contexts finds, however, that log frames with a single sector focus continue to undermine ABP (Sanderson, 2017). In addition, indicators that measure inputs and logistics (e.g. 3,000 houses built) rather than outputs (e.g. degree of satisfaction of users) result in a disincentive to monitor and aim for wider benefits, such as improvements in the lives of urban dwellers (Sanderson, 2017).

\section{Lessons and recommendations}

Defined area: the target area needs to be well focused, characterised by a degree of uniformity in terms of its development challenges, priorities and needs (USWG, 2019; Santini et al., 2012). The target area should cover all similar areas/sub-regions, without reaching a size where the ABP process becomes unmanageable (Saravia-Saravia-Matus et al., 2013; Vrbensky, 2008).

People-centred and participatory-based: effective area-based approaches require meaningful, early and ongoing engagement with all impacted groups in the target area; and assessment of capacities to participate (USWG, 2019; Santini et al., 2012). Participation can be facilitated through community committees and participatory tools and approaches (USWG, 2019). Stakeholders could include local, regional, and national government, civil society, the private 
sector, academics, and diaspora (USWG, 2019; Santini et al., 2012). Rebuilding traditional connections should be supported, particularly in post-conflict settings (Santini et al., 2012).

Realistic time frame and sustainability: it can take time to bring together multiple stakeholders and to build relationships. ABP design and implementation - and related funding - require realistic timeframes (USWG, 2019). By focusing on wider community vulnerabilities and capacities, rather than a specific sector or group (e.g. IDPs), ABP can foster better linkages between acute relief needs, development, and durable solutions (Konyndyk et al., 2020).

Enabling context: according to various urban-based case studies, area-based approaches were more likely to be successful in contexts where there was an existing multi-sectoral coordination system or culture; where communities were more cohesive; and where local government was supportive of ABP and its implementation (USWG, 2019; Sanderson \& Sitko, 2017).

Flexibility: area-based approaches must be flexible, adaptive, and highly responsive to situational changes in the defined area and shifts in priorities, in order to ensure the intervention is constantly relevant (USWG, 2019; Vrbensky, 2008). This applies to programme design, management, funding, and coordination (USWG, 2019; Sanderson \& Sitko, 2017).

Existing systems of local governance: area-based approaches can be strengthened if they work with, and build upon, existing systems of local governance and service delivery (USWG, 2019; Sanderson \& Sitko, 2017). This can include supporting local actors and authorities in defining priorities and delivering public services in the longer-term (USWG, 2019).

Coordination: the creation of a 'platform' (an institutional mechanism for information flow) can bring together a range of sectoral actors (e.g. shelter, WASH, protection, health, livelihoods) to foster a shared understanding and vision, and to plan and implement a collective response (Schell et al., 2020). This can help to counter potential fragmentation associated with local approaches (Vrbensky, 2008).

Monitoring multi-agency contribution: in order to align with the multi-sectoral and multiagency characteristics of ABP approaches, monitoring and evaluation should focus on multiagency contribution to change rather than solely single-agency attribution of outputs to outcomes (USWG, 2019; Sanderson \& Sitko, 2017).

Scaling up: ABP approaches should address the need to scale up, linking with the macro-level, including higher-level government policies and plans, and markets (Sanderson, 2017; Santini et al., 2012). ABP in cities can be strengthened if linked to wider city or regional plans and policies (across multiple sectors and scales), drawing on urban development lessons. This entails, for example, ensuring that neighbourhood plans align with city planning processes, and city plans align with regional strategies (USWG, 2019; Sanderson, 2017). Research on area-based approaches in Afghan cities recommends that CDCs and Gozar Assemblies are integrated into the municipal governance structure, with the aim of linking citizens to municipalities and creating more inclusive and representative institutions (French et al., 2019). It may be necessary to combine ABP with other types of interventions, such as institutional support and advocacy, in order to address policy and institutional reform at higher levels of government (USWG, 2019).

Scaling up also applies to replication of ABP in other geographical areas (Sanderson, 2017). Pilot projects in specific areas can be used to demonstrate results, develop standard tools, and develop the capacity of partners prior to replication (USWG, 2019). In order to have a demonstration effect, the selected areas should not be isolated, but have an interaction with 
other areas (Santini et al., 2012). Cities, such as Tripoli and Beirut in Lebanon, which have implemented 'neighbourhood approaches' have become key sites for learning how to cope with and emerge from multiple and overlapping crises, becoming models for other cities facing complex challenges (Sanyal, 2021). Replication can also help to address the critique of ABP whereby one area receives support while another does not (Sanderson, 2017).

\section{References}

Akbari, M. A., \& Rahmani, O. (2020). The Performance Review of the Community Development Councils from Prospective of Local Governance in Afghanistan. International Journal of Education and Research, 8(1). https://www.ijern.com/journal/2020/January-2020/16.pdf

Ayad, H. M. (2011). Community area-based development in the Northern Region of Syria: Case study of urban Aleppo. Alexandria Engineering Journal, 50(4), 407-419.

https://www.sciencedirect.com/science/article/pii/S111001681100072X

Bogdanov, N., \& Nikolić, A. (2013). Area based development approach-evidence from border rural region Drina-Sava (No. 1543-2016-132191, pp. 101-111). https://ageconsearch.umn.edu/record/161796/

French, M., Popal, A., Rahimi, H., Popuri, S., \& Turkstra, J. (2019). Institutionalizing participatory slum upgrading: a case study of urban co-production from Afghanistan, 2002-2016. Environment and Urbanization, 31(1), 209-230. https://doi.org/10.1177/0956247818791043

González, O. M. (2016). Refugees and 'host communities' facing gender-based violence: developing an area-based approach to gender-based violence around Mbera Camp, Mauritania. Gender \& Development, 24(3), 375-390. https://doi.org/10.1080/13552074.2016.1233669

Harfst, J. (2006). A Practitioner's Guide to Area-Based Development Programming. UNDP. https://www.undp.org/content/dam/undp/library/corporate/speakercorner/a-practitioner-guide-toarea-based-development-programming.pdf

Ilic, B. \& Dzimrevska, I. (2015). Area Based Development Approach in the Western Balkans A tool for rural development with up-scaling potential. CIHEAM. https://www.ciheam.org/publications/141/012__SWG.pdf

Konyndyk, J., Saez, P. \& Worden, R. (2020). Inclusive coordination: Building an area-based humanitarian coordination model. CGDev Policy paper, 184. Washington, DC: Centre for Global Development. https://reliefweb.int/report/world/inclusive-coordination-building-area-based-humanitariancoordination-model

Lillehaugen, $\mathrm{M}$ et al. (2020) Experiences and Expectations in Community-Driven Development: Monitoring Research on Citizens' Charter Afghanistan Project. ATR consulting https://www.acbar.org/upload/15906540559.pdf

Pavloska Gjorgjieska, D., Ilic, B. Mohr, B., Djimrevska, I. and Kolemisevska, K. (2019). Area-Based Development Approach: Improving the Economic Prosperity of Rural Smallholders in the Western Balkans' Cross-Border Regions, IAMO Forum: Small Farms in Transition, 2628 June. https://www.researchgate.net/publication/341151844_Area- 
Based_Development_Approach_Improving_the_Economic_Prosperity_of_Rural_Smallholders_in_the_W estern_Balkans\%27_Cross-Border_Regions

Sanderson, D. \& Sitko, P. (2017): Urban area-based approaches in post-disaster contexts. Guidance note for Humanitarian Practitioners. IIED, London.

https://reliefweb.int/sites/reliefweb.int/files/resources/10825IIED.pdf

Sanderson, D. (2017). Implementing area-based approaches (ABAs) in urban post-disaster contexts. Environment and Urbanization, 29(2), 349-364. https://doi.org/10.1177/0956247817717422

Santini, F., Saravia Matus, S., Louwagie, G., Guri, G., Bogdanov, N., Gomez, Y. \& Paloma, S. (2012). Facilitating an area-based development approach in rural regions in the Western Balkans. (Luxembourg): Publications Office of the European Union. https://ideas.repec.org/p/ipt/iptwpa/jrc68703.html

Sanyal, R. (2021). Making urban humanitarian policy: the "neighbourhood approach" in Lebanon. Urban Geography, 1-21. https://doi.org/10.1080/02723638.2020.1849983

Saravia-Matus, S. L., Louwagie, G., Santini, F., Guri, G., Lazdinis, M., Ilic, B., \& Paloma, S. G. (2013). Challenges to participatory development in a rural cross-border area of the Western Balkans. Economics of Agriculture, 60(3), 623.

https://www.researchgate.net/publication/261296612_Challenges_to_participatory_development_in_a_ rural_cross-border_area_of_the_Western_Balkans

Schell, J., Hilmi, M., \& Hirano, S. (2020). Area-based approaches: an alternative in contexts of urban displacement. Forced Migration Review, (63), 16-19.

https://www.proquest.com/openview/5f5e1a31b491b97ac5590545d5c3743e/1?pq-

origsite $=$ gscholar $\&$ cbl $=55113$

Surlevski, D. et al., (2018). Area Based Development (ABD) - a regional bottom-up approach for sustainable growth of rural livelihoods in the WB crossborder regions. In N. Bogdanov et al. (eds). Application of the LEADER approach in the Western Balkan countries - (SWG). Skopje: Regional Rural Development Standing Working Group in SEE.

https://enrd.ec.europa.eu/sites/default/files/enrd_publications/leader-western-balkans.pdf

UNDP (2018) A primer on area based programming. UNDP Policy brief, issue no. 7. UNDP. https://erc.undp.org/evaluation/managementresponses/keyaction/documents/download/831

UNDP (2014) Assessment of development results: Afghanistan. UNDP Independent Evaluation Office. https://erc.undp.org/evaluation/evaluations/detail/7226

USWG (2019) Area-based approaches in urban settings: Compendium of case studies. Urban Settlements Working Group (USWG). https://reliefweb.int/sites/reliefweb.int/files/resources/201905013_urban_compendium.pdf

Vrbensky, R. (2008). Can development prevent conflict? Integrated area-based development in the Western Balkans-theory, practice and policy recommendations. London: LSE. http://eprints.Ise.ac.uk/23360/1/WP02.pdf 


\section{Suggested citation}

Haider, H. (2021). Area-based programming in fragile- and conflict-affected contexts. K4D Helpdesk Report 1066. Brighton, UK: Institute of Development Studies.

DOI:10.19088/K4D.2022.011

\section{About this report}

This report is based on six days of desk-based research. The K4D research helpdesk provides rapid syntheses of a selection of recent relevant literature and international expert thinking in response to specific questions relating to international development. For any enquiries, contact helpdesk@k4d.info.

K4D services are provided by a consortium of leading organisations working in international development, led by the Institute of Development Studies (IDS), with Education Development Trust, Itad, University of Leeds Nuffield Centre for International Health and Development, Liverpool School of Tropical Medicine (LSTM), University of Birmingham International Development Department (IDD) and the University of Manchester Humanitarian and Conflict Response Institute (HCRI).

This report was prepared for the UK Government's Foreign, Commonwealth and Development Office (FCDO) and its partners in support of pro-poor programmes. Except where otherwise stated, it is licensed for non-commercial purposes under the terms of the Open Government Licence v3.0. K4D cannot be held responsible for errors, omissions or any consequences arising from the use of information contained in this report. Any views and opinions expressed do not necessarily reflect those of FCDO, K4D or any other contributing organisation.

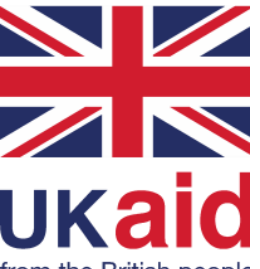

(C) Crown copyright 2021. 